\title{
Traffic Modelling of the Circular Junction in the City of Žilina
}

\author{
Kristián Čulík ${ }^{1 *}$, Veronika Harantová', Alica Kalašová' \\ 1 University of Žilina, Faculty of Operation and Economics of Transport and Communications, ave Univerzitná 1, \\ 01026 Žilina, Slovakia \\ * Corresponding author's e-mail: kristian.culik@fpedas.uniza.sk
}

\begin{abstract}
Nowadays, a high-quality road network is necessary for sustainable transport systems. A sharp rise in automation results in increased transport problems. The most serious problems include the traffic infrastructure congestion, congestion, and increased risk of a traffic accident and, of course, a negative impact on the environment. The mobility of inhabitants and the transport of goods are one of the key transport objectives. A junction still constitutes the most critical point on the road network. That is why crossing the road smoothly and safely makes a large difference for the vehicle. This article provides an analysis of the current state of the selected circular junction. On the basis of the conducted survey, new solutions for this junction were presented, which should prevent the traffic conditions from becoming obtrusive. The Aimsun microsimulation was performed for checking the new proposals.
\end{abstract}

Keywords: junction, circular junction, simulation, transport model

\section{INTRODUCTION}

The growing standard of living affects the increase in the level of motoring. This fact also affects the increase of individual car traffic. Roads are often overloaded, which leads to the congestion. Drivers are often nervous and their behaviour threatens other drivers, thereby reducing the road safety.

Despite the large investments in the infrastructure development, the traffic situation is becoming worse. Roads, junctions and their parts are overloaded everyday - there are many collapses and lack of permeability. The term "capacity of the communications and their equipment" expresses the maximum number of vehicles that can run over the road per time unit. The junction is a point in the communications network where the streams of vehicles are connect, disconnect or cross. In other words, the junction is the point where the road communications intersect or join and at least two are connected [1].

A junction must have sufficient capacity, because it must release all the traffic streams entering it. Otherwise, the vehicles could remain in the junction or before the junction. It is necessary to ensure a continuous, smooth and safe passage of vehicles through the junction. Junctions are classified to three basic groups:

- Uncontrolled junctions - paths of the vehicles are defined by traffic signs, and there are usually two connected roads (main and side road),

- Circular junctions - all vehicles come to the junction with a right turn, then move around the traffic island in centre and then turn right to desired exit.

- Traffic-light-controlled junctions - usually built in one level and the traffic controlled by traffic-light device.

With the appropriate software, it is possible to simulate different types of junctions. Then, the simulation outputs can be processed and reviewed. Traffic simulation is an interesting tool. The advantages of microscopic modelling include the assessment of the future design, the analysis of several aspects of transport infrastructure, etc. Before selecting a suitable type of junction, it is also necessary to analyse its position, transport significance in the area, and its dimensions. The 
output of the simulation should be as optimal as possible and the final variant should take into account all the features of the intersection [2].

\section{Analysis of traffic situation on selected junction}

Žilina is located in the north of the Slovak Republic. It is the fourth largest city and it has an area of approximately $80 \mathrm{~km}^{2}$ with a population of 82,954 inhabitants. An important transport connection between the west and the east of the country passes through the city. The junction is located on the road connecting the city centre with the largest housing estate called Vlčince. The Vysokoškolákov Street is one of the most important roads in transport network of Žilina [3]. Currently, the street has three small, circular, single-lane junctions. Currently, their permeability is limited because on some sections between junctions there are two lanes in each direction connected back to one before the junction. All three junctions are presented in figure 1 .

The solved junction is located in the middle of the street, between two other small circular junctions. It has following entries shown in the figure 2. Entry number 1 leads from the city centre. Entry number 2 connects the junction with the shopping centre. The other two entrances lead to the Vlčince housing estate and surrounding villages.

The small circular junction has an external diameter of 37 meters. Due to frequent

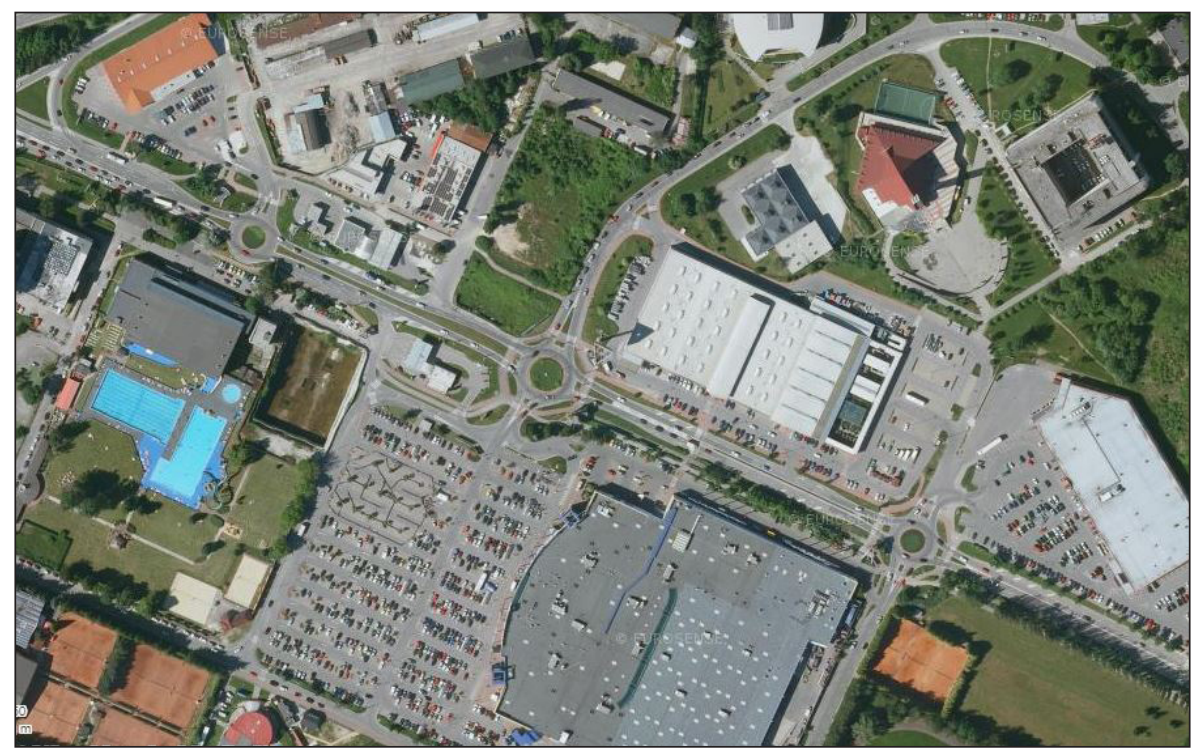

Fig. 1. Small circular junction on Vysokoškolákov Street [4]

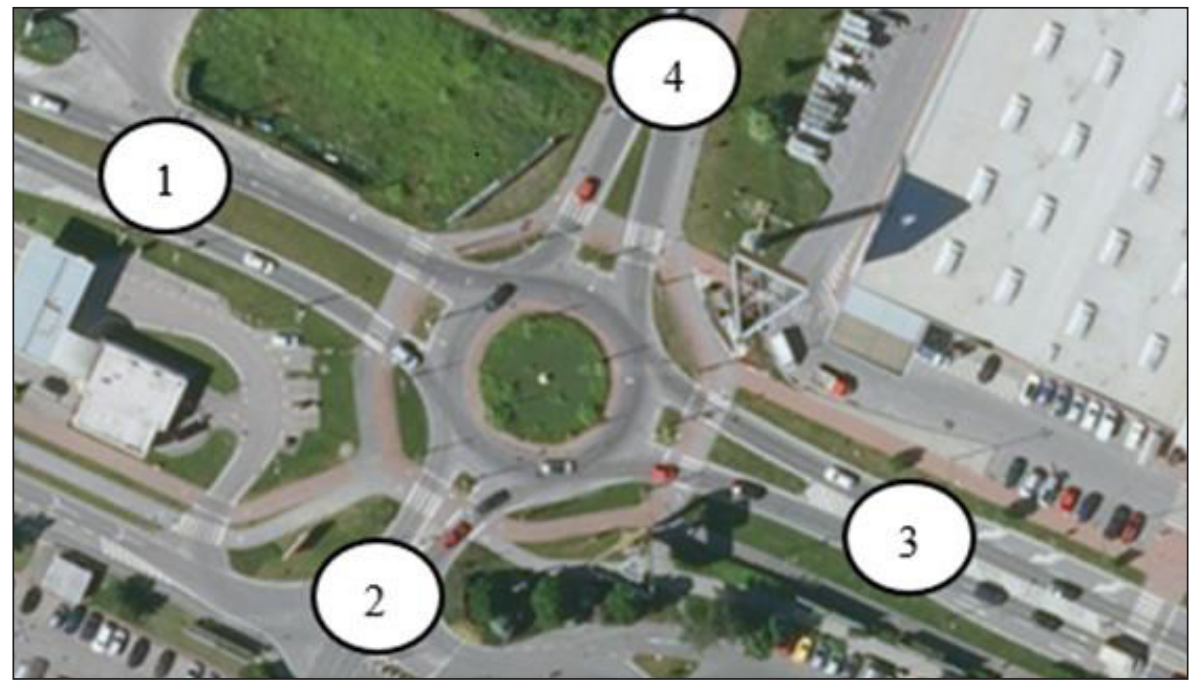

Fig. 2. Marking of each input of the small circular junction [4] 
congestions, it is necessary to find another type of junction with better characteristics. Turbocircular or light-controlled junctions are more powerful than the current one. Changing the type of junction can improve the road traffic situation. In addition, it is also possible to reduce the emissions produced by cars and time spent by people in city centre.

\section{Traffic load of the junction and traffic survey}

A traffic survey was performed on mentioned junction to obtain the necessary data. The survey was performed on $11^{\text {th }}$ October 2018 in the afternoon. The weather was quite sunny without the negative effects of rain. Vehicles were recorded manually by four counting persons to paper sheets. The data were recorded at regular intervals of 15 minutes. After evaluation of the survey, it was possible to find a peak hour. It started at 3:00 pm and ended at 4:00 pm. During this time, 2,666 vehicles passed through the intersection. In addition to the number of passing vehicles, the vehicle types as well as their direction have been recorded. The number of vehicles is shown in Table 1.

The most loaded was entrance number 1 from the city centre with 1,162 vehicles and the exit with the highest load is output number 1 with 1,088 vehicles per hour. The lowest intensity value was recorded for exit number $2-278$ vehicles. All the values from the matrix of load are shown in the figure 3 for a better representation.

During the transport survey, the recorded vehicles were divided into 5 different categories. These categories were created according to the Slovak Technical Conditions TP 102. The following categories with marks were used:

- $\mathrm{C}$ - passenger car,

- $\mathrm{T}$ - truck,

- B - bus, trolleybus,

- M-motorbike,

- B-bicycle.

Table 1. Matrix of vehicle directions during peak hour

\begin{tabular}{|c|c|c|c|c|c|}
\hline O/D & 1 & 2 & 3 & 4 & SUM \\
\hline 1 & $*$ & 150 & 737 & 275 & 1162 \\
\hline 2 & 252 & $*$ & 97 & 98 & 447 \\
\hline 3 & 592 & 40 & $*$ & 43 & 675 \\
\hline 4 & 244 & 88 & 50 & $*$ & 382 \\
\hline SUM & 1088 & 278 & 884 & 416 & 2666 \\
\hline
\end{tabular}

Passenger cars reached the largest proportion of traffic flow composition during the peak hour. Their total number was 2,557 and constituted $95.9 \%$. The second frequent vehicles were lorries. Exactly 71 of them were recorded (2.66\% of vehicles). During the whole survey, only 5 motorcycles were counted $(0.19 \%$ of vehicles). Table number 2 shows all categories of vehicles and their numbers in peak hours.

The percentage of cyclists is very low, so it was not be used to create the simulation.

\section{New designs created with traffic modelling}

Firstly, the current state of junction was verified and evaluated, so the afore-mentioned section of the Vysokoškolákov Street was modelled in the Aimsun software. Aimsun is a traffic modelling software from TSS, a Spanish company based in Barcelona. The Aimsun program enables macroscopic, mesoscopic and microscopic simulations. Various transport networks can also be modelled in Aimsun: urban networks, expressways, motorways, highways, bypasses and their combinations. The target simulation provides several outputs that are divided into these groups: statistics for the whole network, statistics for segments, partition and deviation statistics, track statistics, source/target matrix statistics and public transport statistics. Outputs are generated for each group. These outputs are intensity, density, speed, travel time, delay time, stop time, number of stops, total distance travelled, fuel consumption and produced emissions $[4,5,7]$.

The characteristics of passenger cars, trucks, buses and others were entered as input parameters for modelling. The transport model based on current transport network was designed to be as real as possible. It was modelled for the afternoon peak hour. A transport relationship matrix has been created between the areas.

\section{Making a transport model and using microsimulation}

In total, three transport models (3 types of junctions) were created in the Aimsun simulation program:

- Current small circular junction

- Designed traffic-light-controlled junction

- Designed turbo-circular junction 


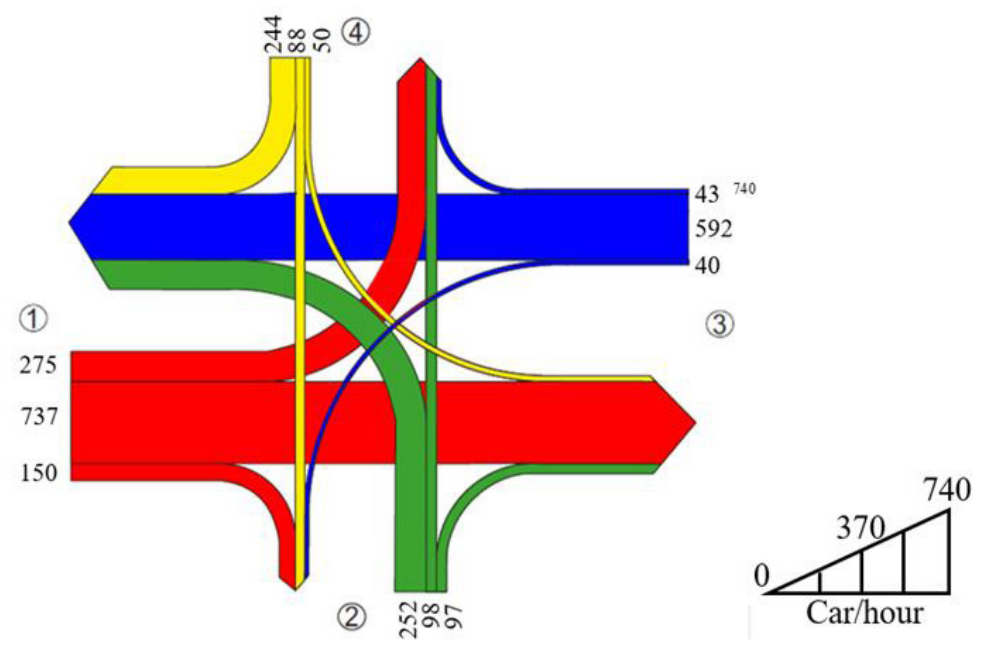

Fig. 3. Graphical representation of the junction load

Table 2. Composition of traffic flow during the peak hour [own study]

\begin{tabular}{|c|c|c|c|c|c|c|}
\hline Category of vehicle & C & T & B & M & B & Sum \\
\hline $15: 00-15: 15$ & 591 & 16 & 6 & 1 & 6 & 620 \\
\hline $15: 15-15: 30$ & 615 & 20 & 4 & 1 & 2 & 642 \\
\hline $15: 30-15: 45$ & 666 & 18 & 5 & 2 & 1 & 692 \\
\hline $15: 45-16: 00$ & 685 & 17 & 4 & 1 & 5 & 712 \\
\hline Sum & 2557 & 71 & 19 & 5 & 14 & 2666 \\
\hline Percentrage & $95.91 \%$ & $2.66 \%$ & $0.71 \%$ & $0.19 \%$ & $0.53 \%$ & $100.00 \%$ \\
\hline
\end{tabular}

All transport models worked with the same input parameters that were obtained during peak hour traffic surveys.

The first step in creating a map layer was to import a communications network from a specific area of the city. The road network has been imported from the Open Street Map database in the correct scale. The same lane width and maximum speed were set for all three models. In total, 10 simulations were carried out for each model. From the simulation, an average was created. Then, the obtained values such as delay time, stop time, travel time, number of stops, density, speed and intensity were compared. Delay time and travel time were also shown graphically according to the vehicle type.

\section{Current situation}

The transport model reflects the current traffic situation. It is shown in figure 4 . The output values of this microsimulation were compared with values of the other two proposals. An assessment of the current situation and proposals is described in the last chapter of this paper.

\section{The first proposal - traffic-light- controlled junction}

The first proposal is changing the current junction to a traffic-light-controlled junction. The number of lanes for each entrance and output was created according to TP 102. The capacity of one lane was limited to a maximum of 500 cars per hour [2]. On the basis of this condition, 4 entrance lanes and 2 exit lanes were created on the first arm of the junction. Arm number 3 consisted of 3 lanes at the entrance and 2 lanes at the exit. The arms number 2, 4 had the same number of lanes at the entrance (two) and only one exit lane. This is shown in Figure 5.

Another important step for the correct making of the transport model is creating of a trafficlight-signalling plan. The lengths of the green light and the total number of signal groups were generated according to the procedure described in the technical condition TP 102. The final light signalling plan was calculated with a cycle of 60 seconds, and offset of 2 seconds and a $3 \mathrm{sec}-$ onds yellow light. The entire signalling plan is shown in Figure 6. 


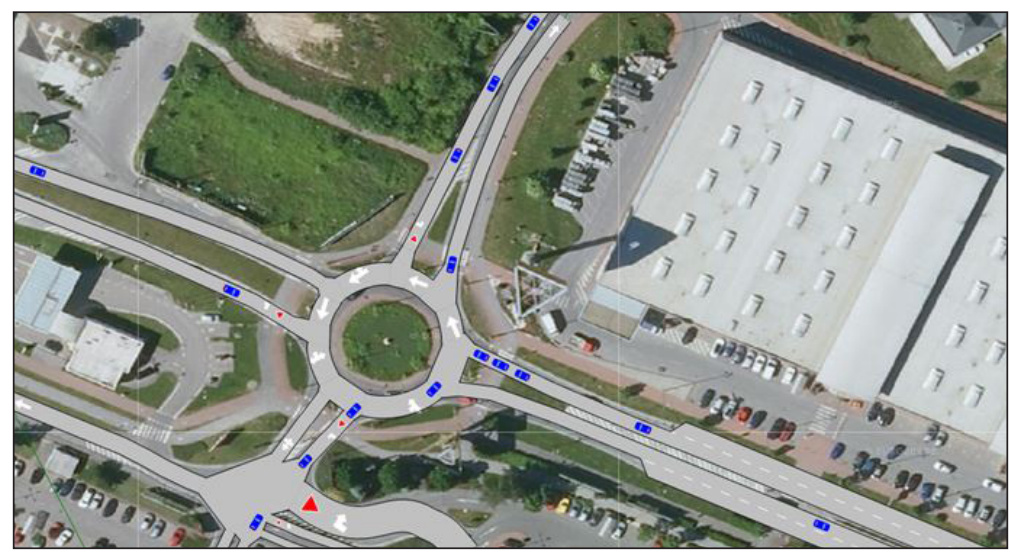

Fig. 4. Small circular junction in software Aimsun

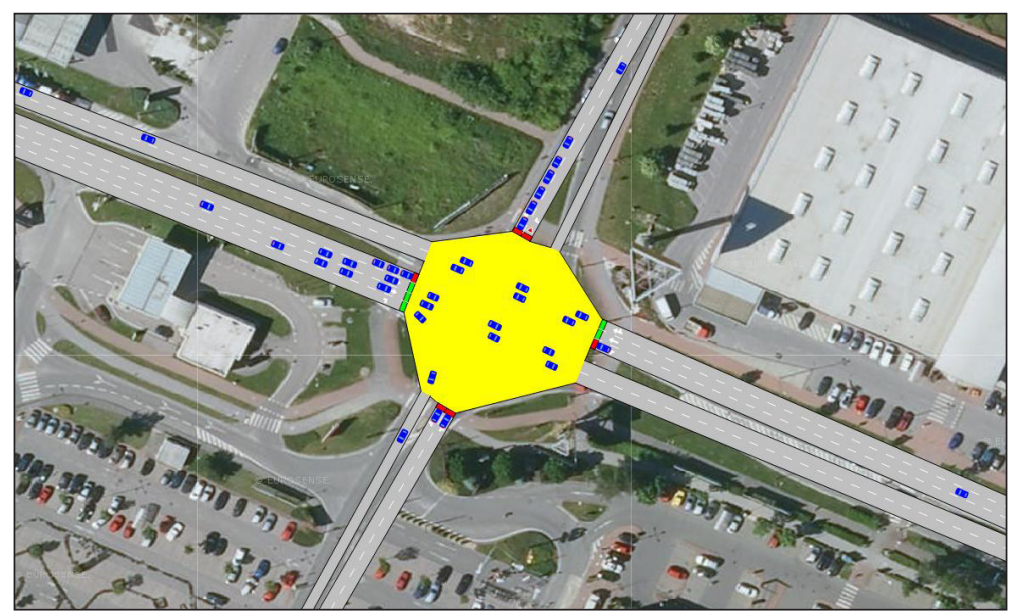

Fig. 5. The first proposal - traffic-light-controlled junction

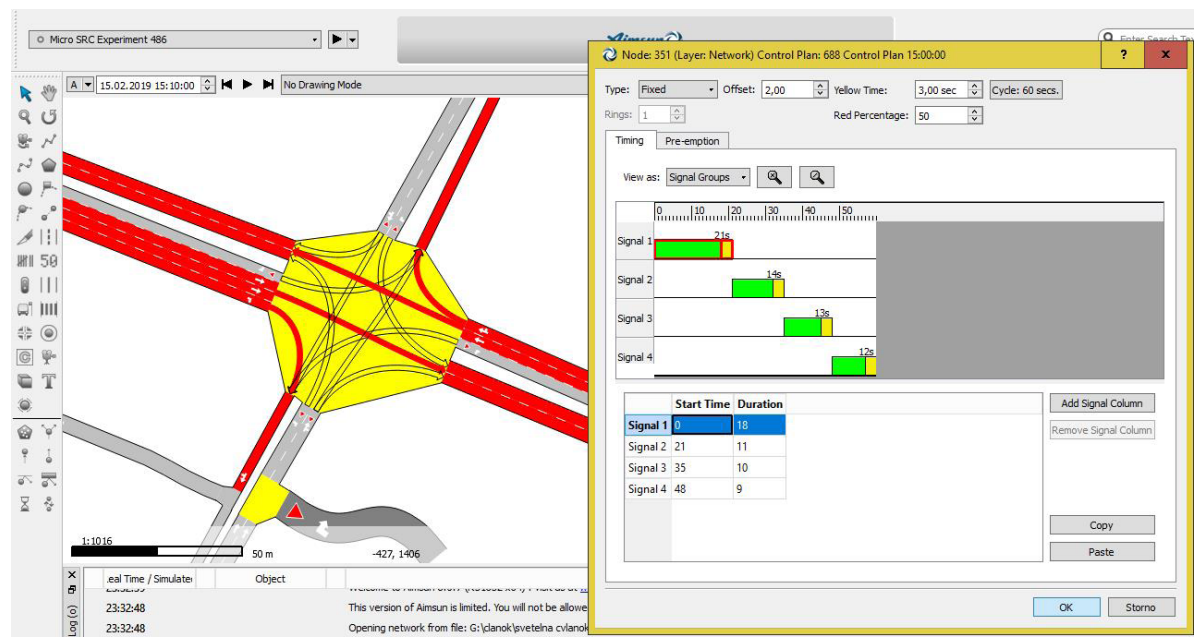

Fig. 6. Created a traffic-light-signalling plan

\section{The second proposal - turbo-circular junction}

The second proposal was creating a turbocircular junction. This type of junction should provide greater safety and capacity compared to a classic two-lane or multi-lane circular junction. The advantage of a turbo-circular junction is a shape of driving lanes on a circuit. Vehicles must to be in the appropriate lane before the junction if they want to leave it with desired direction [6]. 


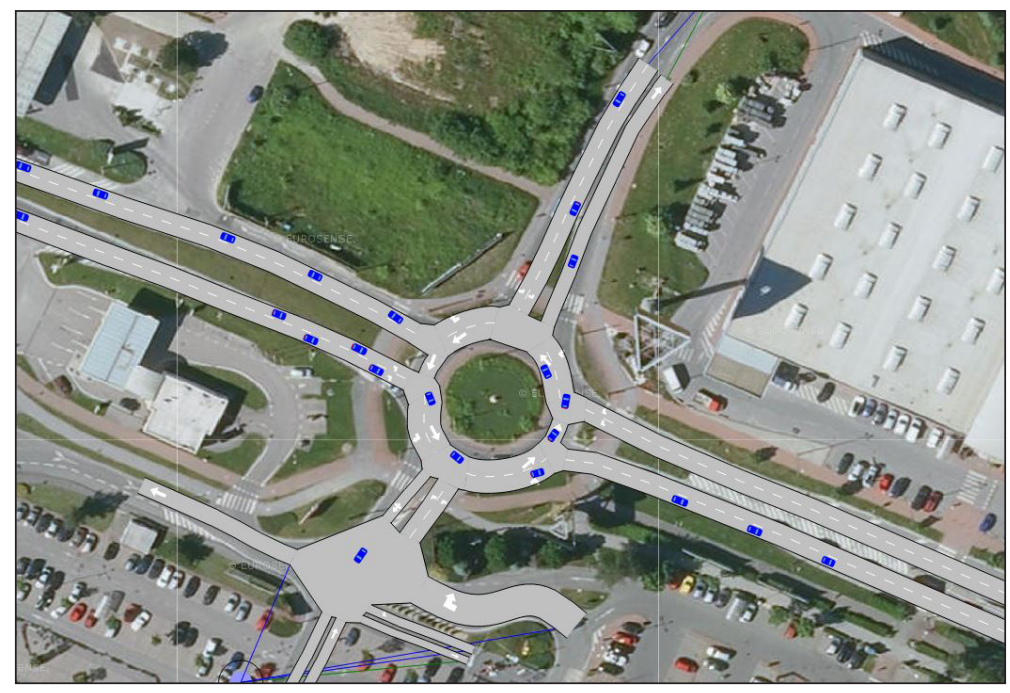

Fig. 7. The second proposal - turbo-circular junction

\section{Creating of traffic model with microsimulation}

Ten simulations were performed for each transport model. The average was calculated from the simulation, and the resulting values were used later. The simulation started when the peak hour was recorded. In the previous figures 4,5 and 7 it is possible to see the course of the simulation for all three types of junctions.

The output indicators that have been recorded and compared between each type of junction are delay time, stop time, travel time, number of stops. Of course, three basic characteristics of the transport stream density, intensity and speed were also observed. All these indicators were analysed and then compared between the current circular junction and the two proposals of new junction. Each simulation lasted one hour. The Tables 3 and 4 compare the resulting values between the current state and the new proposals.

From the previous tables it is obvious that for the both proposals, the resulting values decreased by $50 \%$ except for the intensity.

The density achieved the most significant decrease in the first proposal by $67 \%$ compared to the current intersection. The number of stops has the second-largest decrease by $65 \%$ in the first proposal, too. Stop time and delay time decreased

Table 3. Comparison of values from simulation for the current state and first proposal

\begin{tabular}{|l|c|c|c|c|}
\hline \multicolumn{1}{|c|}{ Parameter } & Current status & Traffic light & Unit & Change (\%) \\
\hline Number of stops & 3,60 & 1,24 & $-/ \mathrm{veh} / \mathrm{km}$ & $-65,56$ \\
\hline Delay time & 262,37 & 142,91 & $\mathrm{sec} / \mathrm{km}$ & $-45,53$ \\
\hline Stop time & 234,22 & 126,31 & $\mathrm{sec} / \mathrm{km}$ & $-46,07$ \\
\hline Travel time & 332,51 & 209,60 & $\mathrm{sec} / \mathrm{km}$ & $-36,96$ \\
\hline Density & 47,77 & 15,68 & $\mathrm{veh} / \mathrm{km}$ & $-67,18$ \\
\hline Speed & 18,91 & 26,56 & $\mathrm{~km} / \mathrm{h}$ & $+40,45$ \\
\hline Flow & 2500,60 & 2705,20 & $\mathrm{veh} / \mathrm{h}$ & $+8,18$ \\
\hline
\end{tabular}

Table 4. Comparison of values from simulation for the current state and second proposal

\begin{tabular}{|l|c|c|c|c|}
\hline \multicolumn{1}{|c|}{ Parameter } & Current status & Turbo-circular junction & Unit & Change (\%) \\
\hline Number of stops & 3,60 & 1,81 & $-/ \mathrm{veh} / \mathrm{km}$ & $-49,72$ \\
\hline Delay time & 262,37 & 132,31 & $\mathrm{sec} / \mathrm{km}$ & $-49,57$ \\
\hline Stop time & 234,22 & 103,29 & $\mathrm{sec} / \mathrm{km}$ & $-55,90$ \\
\hline Travel time & 332,51 & 203,09 & $\mathrm{sec} / \mathrm{km}$ & $-38,92$ \\
\hline Density & 47,77 & 24,09 & $\mathrm{veh} / \mathrm{km}$ & $-49,57$ \\
\hline Speed & 18,91 & 26,75 & $\mathrm{~km} / \mathrm{h}$ & $+41,46$ \\
\hline Flow & 2500,60 & 2589,80 & $\mathrm{veh} / \mathrm{h}$ & $+3,57$ \\
\hline
\end{tabular}


by about $46 \%$, and travel time decreased by about $37 \%$. By using the first proposal instead of the current small circular junction, an increase of $8 \%$ was reached in the junction performance.

Three indicators reached even lower values in the second proposal. The greatest improvement was reached the stopping time by almost $56 \%$. It also reduced travel time by $2 \%$ and delay time by $4 \%$ compared to the first proposal. Speed of the vehicles increased by $1 \%$.

Reduction of some indicators caused that vehicles lost less time in traffic jams. They produced lower value of emissions because the passage of the vehicle through the junction was smoother.

Figures 8 and 9 show two indicators: stop time and travel time indicators for the current roundabout, first draft and second draft. The indicators are different for three categories of vehicles (car, truck, bus) and for all vehicles.

From the view of assessing the quality of traffic flow, the indicators include delay time and travel time to the most important ones. The output values from the simulation are in the figures 8 and 9. The averages of the individual vehicle categories are significantly lower for both new proposals than for the current roundabout.

\section{CONCLUSION}

The aim of this article was to evaluate the traffic situation at a selected roundabout in Žilina. The current traffic situation is complicated, especially during the peak hours. Then, the traffic

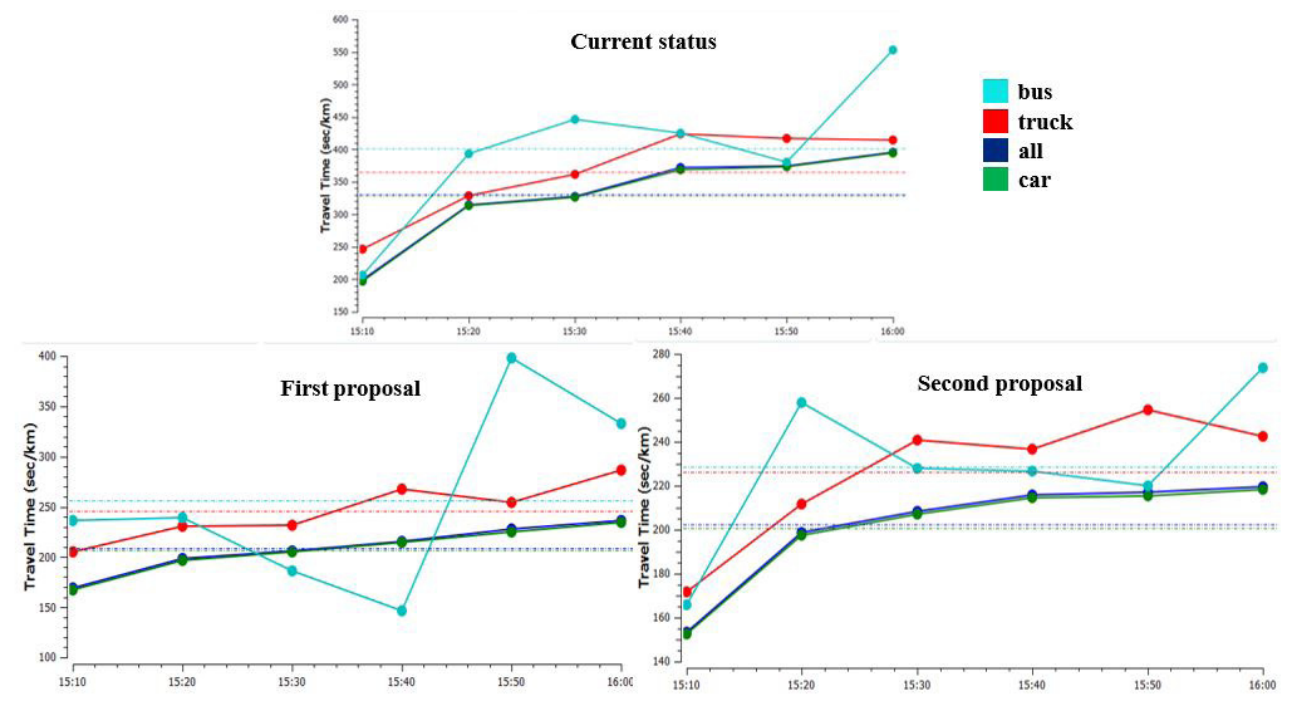

Fig. 8. Travel time according to vehicle category

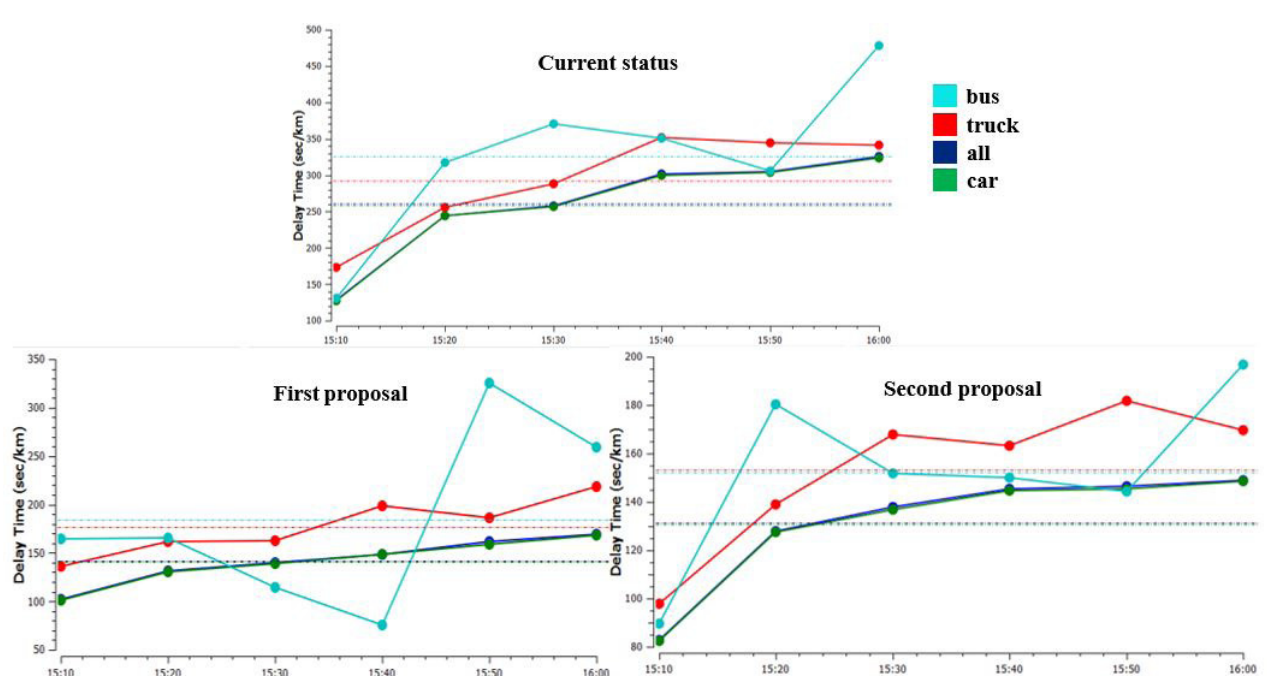

Fig. 9. Delay time according to vehicle category 
congestions are formed near the junction, which slow down the entire traffic flow of vehicles passing through this node. Two different solutions were proposed: traffic-light-controlled junction and turbo-circular junction. Three transport models were created using microsimulation. As the simulation showed, the number of stops, density, and intensity increased significantly with using the trafficlight-controlled junction. However, the turboroundabout has significantly reduced up to three variables, namely stop time, delay time and travel time. According to the simulation results, the second proposal seems to be a better one. Ultimately, it can be assumed that both proposals can improve the current traffic situation of the circular junction.

\section{Acknowledgement}

This work was supported in part by the Grant VEGA no. 1/0436/18 - Externalities in road transport, an origin, causes and economic impacts of transport measures.

\section{REFERENCES}

1. Ministry of Transport and Construction of the Slovak Republic: Technical Conditions 102, Calcula- tion of Road Communications Capacity. Ministry of Transport and Construction of the Slovak Republic, Slovak Republic, 2015.

2. Culik, K., A. Kalasova and S. Kubikova. Simulation as an Instrument for Research of Driver-vehicle Interaction. In 18th International Scientific Conference on LOGI. Ceske Budejovice, Czech Republic: E.D.P. Sciences, 2017, vol. 134.

3. Kubikova, S., A. Kalasova and L. Cernicky. Microscopic Simulation of Optimal Use of Communication Network. In J. MIKULSKI ed. Telematics - Support for Transport. Berlin: Springer-Verlag Berlin, 2014, 471, 414-423.

4. Gnap, J., V. Konecny and M. Poliak Demand elasticity of public transport. Ekonomicky Casopis, 2006, 54(7), 668-684.

5. Gnap, J., V. Konecny, R. Slavik and D. Benova Possible Impacts of Regulating the Weekly Rest of Road Freight Drivers on Logistics in EU Countries. Nase More, 2018, 65(4), 259-265.

6. Poliak, M. Impact of Road Network Charging System on Pricing for General Cargo Transportation. Promet-Traffic \& Transportation, 2012, 24(1), 25-33.

7. Poliak, M. The Relationship with Reasonable Profit and Risk in Public Passenger Transport in the Slovakia. Ekonomicky Casopis, 2013, 61(2), 206-220. 